\title{
Less common genotype variants of TP53 polymorphisms are associated with poor outcome in adult patients with adrenocortical carcinoma
}

\author{
Britta Heinze ${ }^{1}$, Leonie J M Herrmann ${ }^{1}$, Martin Fassnacht ${ }^{1,2}$, Cristina L Ronchi' \\ Holger S Willenberg ${ }^{3}$, Marcus Quinkler ${ }^{4}$, Nicole Reisch ${ }^{2}$, Martina Zink ${ }^{1}$, \\ Bruno Allolio ${ }^{1}$ and Stefanie Hahner ${ }^{1}$ \\ ${ }^{1}$ Endocrinology and Diabetes Unit, Department of Internal Medicine I, University Hospital of Wuerzburg, University \\ of Wuerzburg, Oberduerrbacher Strasse 6, D-97080 Wuerzburg, Germany, ${ }^{2}$ Department of Endocrinology, \\ Medizinische Klinik und Poliklinik IV, Hospital of the University of Munich, D-80336 Munich, Germany, ${ }^{3}$ Department \\ of Endocrinology and Diabetology, Medical Faculty Duesseldorf, Moorenstrasse 5, D-40225 Duesseldorf, Germany \\ and ${ }^{4}$ Clinical Endocrinology, Charité Campus Mitte, Charité University Medicine Berlin, D-10117 Berlin, Germany
}

Correspondence should be addressed to S Hahner

Email

hahner_s@

medizin.uni-wuerzburg.de

\begin{abstract}
Context: The Li-Fraumeni tumor syndrome is strongly associated with adrenocortical carcinoma (ACC) and is caused by germline mutations in TP53 in 70\% of cases. Also, TP53 polymorphisms have been shown to influence both cancer risk and clinical outcome in several tumor entities. We, therefore, investigated TP53 polymorphisms in a cohort of adult patients with ACC.

Objective: Evaluation of the role of TP53 polymorphisms in adult patients with ACC.

Subjects and methods: Peripheral blood for DNA extraction was collected from 72 ACC patients. Polymorphism analysis was carried out by amplification and sequencing of exons and adjacent intron sections of TP53. Results were correlated with clinical data and the distribution of the polymorphisms was compared with published Caucasian control groups. Results: Compared with control groups, genotype frequencies of analyzed TP53 polymorphisms among ACC patients were significantly different in three out of four polymorphisms: IVS2 + 38G $>C$ (G/G, $P=0.0248$ ), IVS3ins 16 (NoIns/Nolns, $P<0.0001$; Nolns/Ins, $P<0.0001)$, and IVS6 $+62 \mathrm{~A}>\mathrm{G}(\mathrm{G} / \mathrm{G}, P<0.0001 ; \mathrm{G} / \mathrm{A}, P<0.0001)$. Overall, the survival of ACC patients, which harbored at least one of the less frequent genotype variants of four analyzed polymorphisms $(n=23)$, was significantly inferior (median survival: 81.0 months in patients with the common homozygous genotypes vs 20.0 months in patients with the less frequent genotypes, $\mathrm{HR} 2.56,95 \% \mathrm{Cl} 1.66-7.07 ; P=0.001)$. These results were confirmed by multivariable regression analysis (HR 2.84, 95\% Cl 1.52-7.17; $P=0.037$ ).

Conclusion: Some TP53 polymorphisms seem to influence overall survival in ACC patients. This effect was observed for a combination of polymorphic changes rather than for single polymorphisms.
\end{abstract}

\section{Introduction}

TP53 is a well-known tumor suppressor gene located on chromosome $17 \mathrm{p} 13$ with mutations frequently observed in many types of human cancers $(1,2)$. The corresponding protein p53 is a transcription factor that regulates the expression of stress-response genes and mediates a variety of antiproliferative processes (3). Polymorphisms of TP53 alleles occurring in the same population are often defined as single-nucleotide polymorphism (SNP) in coding and (c) 2014 European Society of Endocrinology Printed in Great Britain
Published by Bioscientifica Ltd. 
noncoding regions but also comprise deletions or insertions of one or more nucleotides.

More than $90 \%$ of the polymorphisms identified so far are localized in intronic regions $(1,2)$, with a $16 \mathrm{bp}$ insertion as the most frequently described polymorphism in intron 3 (c.96+41_96+56del16, SNP no. 17878362 , named IVS3ins16, Fig. 1). IVS3ins16 is correlated with an increased risk of various cancers, including ovary (4), lung (5), colon (6), and breast cancer (7). Another wellcharacterized intron polymorphism is located in intron 6 (c. $672+62 \mathrm{~A}>\mathrm{G}$, SNP no. 1625895, named IVS6 +62A > G, Fig. 1), which is associated with lower apoptotic indices and DNA repair capacity (5). To our knowledge, no functional information has yet been published concerning the polymorphism described in intron 2 (c. $74+38 \mathrm{G}>\mathrm{C}$, SNP no. 1642785 , named IVS2+38G $>$ C, Fig. 1) $(8,9)$.

The most frequently investigated exonic polymorphism is located in exon 4 of TP53, codon 72 (R72P, SNP no. 1042522, Fig. 1) and has been mainly discussed as a susceptibility factor for different malignancies. The R72P polymorphism leads to an arginine (Arg) to proline (Pro) substitution, which results in a structural alteration of the protein (10). Geographical differences in distribution have been observed, which depend mainly on latitude $(11,12)$. So far, the role of the proline-rich domain in the regulation and function of p53 is, however, unclear (2). Several studies have reported that the arginine variant of R72P induces apoptosis more potently and protects cells

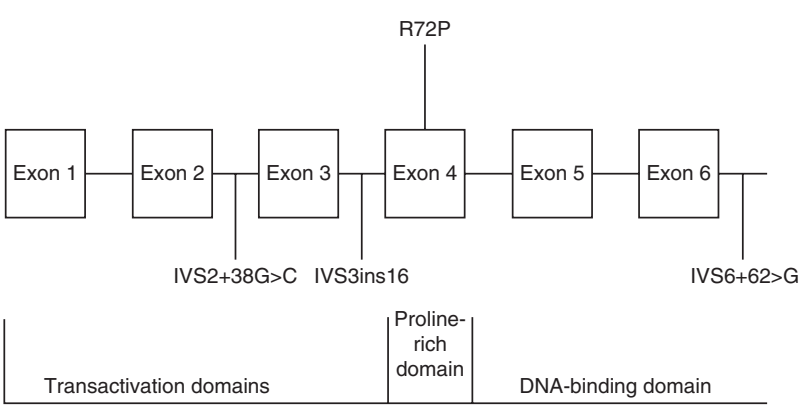

\section{Figure 1}

Scheme of three TP53 intron polymorphisms and one exon polymorphism. The polymorphism (intron 2 (c.74+38G $>C$, SNP no. 1642785 , named IVS2 + 38G $>$ C), intron 3 (c.96+ 41_96+56del16, SNP no. 17878362, named IVS3ins16), intron 6 (c.672+62A > G, SNP no. 1625895, named IVS6+62A $>$ G) and one exon polymorphism: exon 4 of TP53, codon 72 (R72P) discussed in the text) are shown in the figure as well as the localization in the corresponding protein domain. better from neoplastic transformation than the proline variant $(2,10,13,14)$. Up to now variable results about the association of $\mathrm{R} 72 \mathrm{P}$ with cancer risk have been published $(2,7,15,16,17,18)$. Murata et al. (18) reported lung cancer to be associated with the arginine variant of the R72P polymorphism, whereas others observed a higher prevalence of the proline variant compared with controls in such patients (17). In the only previous study on TP53 polymorphisms in ACC patients, a threefold higher prevalence of the proline variant of the R72P polymorphism compared with controls was observed (19).

So far, most studies concentrate on a single polymorphism and only a few studies have considered two or more polymorphisms in the same series $(7,15,20,21)$. Hrstka et al. (15) showed a positive correlation of lymph node metastases in breast cancer patients with IVS3ins16 and IVS6 $+62 \mathrm{~A}>\mathrm{G}$ polymorphisms. Another study described a prognostic effect of the multivariant alleles from R72P and IVS3ins16, resulting in a significantly poorer prognosis in non-small cell lung cancer (21). Costa et al. (7) described that TP53 polymorphisms (IVS3ins16 and R72P) are associated with a higher incidence of lymph node metastases. Analyzing the three polymorphisms R72P, IVS3ins16, and IVS6 $+62 \mathrm{~A}>\mathrm{G}$ in 107 patients, Wang-Gohrke et al. (16) concluded that the rare alleles of IVS3ins16 and R72P of p53 may modify the risk of breast cancer in German women. All these data suggest a role of multiple TP53 polymorphisms to predict incidence and survival in different cancers.

Adrenocortical carcinoma (ACC) is a rare malignancy of the adrenal cortex with an incidence of 1-2/1 000000 population $(22,23)$ and a poor prognosis with a median OS of only 3.5 years $(24,25,26,27,28,29)$. It is part of the Li-Fraumeni tumor syndrome and thus specifically linked to germline mutations in $\operatorname{TP53}(30,31)$. Accordingly, TP53 polymorphisms and their impact on p53 function may be particularly relevant in ACC. This assumption is supported by a small study from Poland that determined the sequence variants of the R72P polymorphism in a cohort $(n=17)$ of patients with ACC in comparison with a healthy control group and identified a threefold higher prevalence of the proline allele in codon 72 in patients with ACC. They concluded that the proline genotype may represent a possible risk factor for the development of ACC (19).

To further elucidate a possible role of TP53 germline polymorphisms in ACC, we investigated a larger cohort of adult patients with ACC derived from the German ACC registry $(24,32)$ and included in our analysis not only 
the exon 4 polymorphism but also the three described intron polymorphisms.

\section{Subjects and methods}

\section{Patients and samples}

We studied 72 patients with ACC registered with the German ACC Registry $(33,34)$, in whom germline DNA and consent for genetic analyses were available (www. nebennierenkarzinom.de). This registry was established in 2003 and at the time of the last analysis (March 2012) comprised $>700$ patients. All data sets were collected by trained medical personnel as described previously (24). In addition histories of patients who had recorded malignancies before ACC diagnosis were also considered. There was no difference in prior malignancies between the common and the rare variants of TP53 polymorphism. Contact to the registry is made either by the local attending physician or by the patient or his/her relatives. Patients had been recruited to the German ACC Registry from all over Germany; all patients were Caucasians. The patients had undergone clinical, radiological, and hormonal examination followed by surgery. Histopathological evaluation of adrenal tissue including assessment of Weiss score (35) was used to establish the diagnosis of ACC. Clinical stage was determined according to ENSAT classification (24). Ethical approval (No. 93/02) was obtained from the local Ethics Committee at the University of Wuerzburg and the participating centers in Germany, and patients gave written informed consent. Information from hospital records and blood samples was provided by the respective supervising clinics. The distribution of TP53 polymorphisms in Caucasian reference populations was taken from the literature $(9,36,37)$ : for R72P and IVS3ins16, 563 German healthy controls (327 (58.1\%) males and 236 (41.9\%) females, with a mean age of 66.9 years) were available (37); for IVS6 $+62 \mathrm{~A}>\mathrm{G}$ controls were Caucasians born in Italy, 177 (60\%) were male, and 118 were female (40\%), the mean age was 63.5 years (36); and for IVS2 $+38 \mathrm{G}>\mathrm{C}$ we used 72 healthy Danish women with a median age of 61 years as controls (9). The observed TP53 polymorphisms were also checked against the database http://gvs.gs.washington.edu/GVS137/. Here the global minor allele frequency (MAF) for the various SNPs are as follows: intron 2 SNP no. 1642785: $\mathrm{MAF}=$ 26\%; intron 3 (SNP no. 17878362): $\mathrm{MAF}=50 \%$; intron 6 SNP no. 1625895: $\mathrm{MAF}=18 \%$; $\mathrm{R} 72 \mathrm{P}$ exon 4 , codon 72 SNP no. 1042522: $\mathrm{MAF}=23 \%$.

\section{DNA extraction}

Peripheral blood (1-5 ml) was collected from all patients and genomic DNA was extracted from blood samples using the FlexiGene DNA Extraction Kit (Qiagen).

\section{PCR and sequence analysis}

For sequence analysis of the TP53 exons and introns from genomic DNA, the samples were amplified by PCR using primers according to the design of BioGlobe $\mathrm{GmbH}$, Hamburg, Germany (Metabion International AG, PlaneggMartinsried, Germany) with $1 \times$ Hotstar Buffer (Qiagen), $1.5 \mathrm{mM} \mathrm{MgCl}_{2}, 200 \mu \mathrm{M}$ of each dNTPs (Fermentas Life Sciences, Schwerte, Germany), 2 U HotStar DNA polymerase (Qiagen), and $0.4 \mu \mathrm{M}$ of each primer. PCR comprised 35 cycles $\left(94^{\circ} \mathrm{C}\right.$ for $60 \mathrm{~s}, 63^{\circ} \mathrm{C}$ for $60 \mathrm{~s}$, and $72{ }^{\circ} \mathrm{C}$ for $60 \mathrm{~s}$ ) with $25 \mathrm{ng}$ of genomic DNA; final extension was at $72^{\circ} \mathrm{C}$ for $10 \mathrm{~min}$. Before cycle sequencing, PCR products were purified using Agencourt AMPure (Beckman-Coulter, Krefeld, Germany). For cycle sequencing of TP53 exon PCR products, BigDye Terminator v3.1 Cycle Sequencing Kit (Applied Biosystems) was used. Each $10-\mu$ reaction contained $1 \mu \mathrm{l}$ BigDye reaction mix and 5 pmol of forward or reverse primer (according to Bioglobe $\mathrm{GmbH}$ ) respectively. Cycle sequencing comprised 35 cycles $\left(96^{\circ} \mathrm{C}\right.$ for $10 \mathrm{~s}, 55^{\circ} \mathrm{C}$ for $5 \mathrm{~s}$, and $60{ }^{\circ} \mathrm{C}$ for $\left.4 \mathrm{~min}\right)$. Sequence reactions were purified using Agencourt CleanSEQ (Beckman-Coulter). Samples were subjected to capillary electrophoresis on a MegaBACE 1000 DNA Analyzer. Electrokinetic injection was $2 \mathrm{kV}$ for $12 \mathrm{~s}$ and electrophoresis was continued at $8 \mathrm{kV}$ for $110 \mathrm{~min}$. All sequence data were analyzed using GENtle (Manske $M$, University of Cologne, Germany, http://gentle.magnusmanske.de/) and 4 peaks (Mekentosj, http://mekentosj. com/4peaks).

The four most often described TP53 polymorphisms were analyzed: one exonic polymorphism located in exon 4 (R72P) and three intronic TP53 polymorphisms: IVS2+ $38 \mathrm{G}>\mathrm{C}($ c. $74+38 \mathrm{G}>\mathrm{C}, \mathrm{SNP}$ no. 1642785), IVS3ins16 (c.96+41_96+56del16, SNP no. 17878362), and IVS6+ $62 \mathrm{~A}>\mathrm{G}$ (c.672+62G $>$ A, SNP no. 1625895). Exemplary chromatograms for each of the four analyzed polymorphisms are shown in Fig. 2.

\section{Statistical analyses}

Clinical parameters, such as age at diagnosis, tumor size, tumor stage (ENSAT) between groups with the common and rare variants of TP53 polymorphisms, were compared by $\chi^{2}$ test. Fisher's (F) exact test was used to investigate 

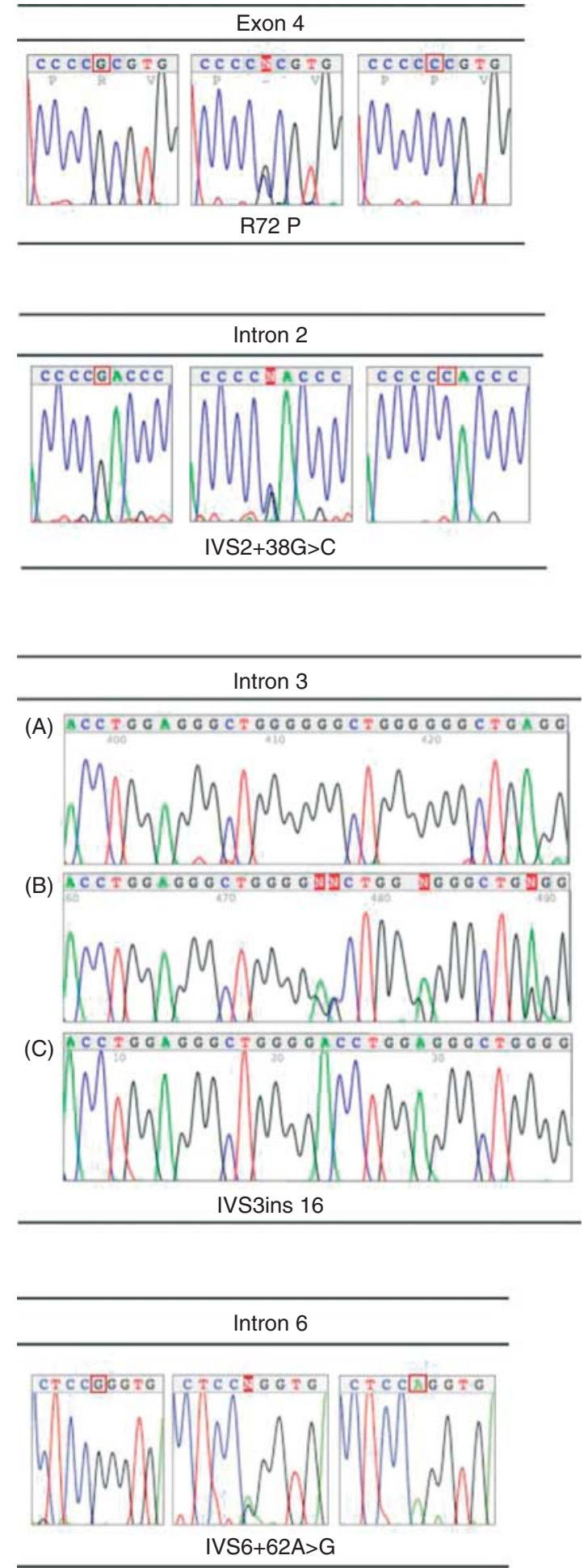

Figure 2

Exemplary chromatograms for each of the four analysed polymorphisms. R72P, IVS2 + 38G > C, IVS3ins16 ((A) sequence with no insertion, (B) heterozygous insertion, $(C)$ homozygous insertion) and IVS6 $+62 \mathrm{~A}>\mathrm{G}$. dichotomous variables, such as differences in the frequency of genotype distribution in case and control groups (i.e. two groups and three conditions). To assess whether the presence of a less frequent TP53 allele influences OS and could be used as a predictive marker, Kaplan-Meier survival analysis was carried out for calculation of median duration and $95 \%$ CI. OS was defined as the time from the date of primary diagnosis to death or last follow-up. Genotype distribution was investigated for the presence of HardyWeinberg equilibrium. Multivariable regression analysis was carried out by the Cox proportional hazards regression model to identify factors (TP53 polymorphisms, ENSAT stage, age, Ki67 index, involvement of lymph nodes, and vessel infiltration) that might have influenced survival. For all parameters showing significance in univariable analysis, multivariable regression analysis was carried out. The statistical analysis was carried out with SPSS software package (version 15.0.) and using GraphPad Prism (version 5.0, La Jolla, CA, USA). Results are given as hazard ratios (HR) including 95\% CI and a significance level of $P<0.05$ was considered to be statistically significant for each analysis.

\section{Results}

\section{Patients}

The clinical data of the 72 Caucasian patients from the German ACC registry are given in Table 1 . Median age at primary diagnosis was 48 years (range 18-79 years), 30 (41.7\%) were male and 42 (58.3\%) were female. Follow-up information was available for all patients, with a median follow-up of 34.2 months (Table 1).

\section{Distribution of four TP53 polymorphisms in ACC patients}

To assess a possible deviation of the distribution of the four analyzed polymorphic genotypes we compared ACC patients with Caucasian reference populations $(9,36,37)$. The only previously described polymorphism in ACC patients is located in exon 4, codon 72 (R72P) (19). The more frequent genotype $(\mathrm{G} / \mathrm{G})$ was found in our collective in 51 patients $(70.8 \%)$ and the less frequent genotypes (G/C $n=17, \mathrm{C} / \mathrm{C} n=4)$ in 21 patients $(29.2 \%)$. The genotype distribution of R72P between cases and controls (G/G 61\% (n=343), G/C ( $n=193)$, and C/C $(n=27) 39 \%)$ did not differ significantly (Fig. 3). The observed TP53 polymorphisms were also checked against the database http://gvs.gs.washington.edu/GVS137/ (see also the section Patients and samples). For R72P we observed a good 
Table 1 Clinical data of patients with ACC $(n=72)$.

\begin{tabular}{|c|c|}
\hline & $n=72$ \\
\hline \multicolumn{2}{|l|}{ Sex } \\
\hline Male & 30 \\
\hline Female & 42 \\
\hline \multicolumn{2}{|l|}{ Age at PD (years) } \\
\hline Median (range) & $48(18-78)$ \\
\hline \multicolumn{2}{|l|}{ Tumor size $(\mathrm{cm})$} \\
\hline Median (range) & $10.5(3-30)$ \\
\hline \multicolumn{2}{|c|}{ ENSAT stage at diagnosis (\%) } \\
\hline I & 7.0 \\
\hline II & 35.2 \\
\hline III & 26.8 \\
\hline IV & 31.0 \\
\hline \multicolumn{2}{|c|}{ Hormone activity (\%) } \\
\hline Yes $^{a}$ & 56.9 \\
\hline No & 29.2 \\
\hline ND & 13.9 \\
\hline Alive patients & 26 \\
\hline \multicolumn{2}{|c|}{ Time of follow up ${ }^{b}$ (months) } \\
\hline Median (range) & $49(9.4-339)$ \\
\hline \multicolumn{2}{|l|}{ Overall survival' ${ }^{c}$} \\
\hline Median (range) & $33.3(4.2-339)$ \\
\hline
\end{tabular}

correlation of our control groups with the large database (R72P exon 4, codon 72 SNP no. 1042522: global MAF = $23 \%)$. The genotype distribution for insertion of the 16-bp duplication polymorphism (IVS3ins16) was $90.3 \%(n=65)$ for homozygotes (NoIns), 5.6\% $(n=4)$ for heterozygotes, and $4.2 \%(n=3)$ for homozygotes (Ins) in ACC patients. In the Caucasian reference populations the genotype distribution was $68.4 \%(n=385), 29.5(n=166)$, and $2.1 \%(n=12)$ for homozygotes (NoIns), heterozygotes, and homozygotes (Ins) respectively (NoIns/NoIns, $P<0.0001 ;$ NoIns/Ins, $P<0.0001)$. For the IVS3ins 16 polymorphism a deviation from the database http://gvs. gs.washington.edu/GVS137/ is shown (intron 3 (SNP no. 17878362): $\mathrm{MAF}=50 \%$ ). A significantly altered distribution in comparison with the selected Caucasian control group was also found in relation to IVS2 $+38 \mathrm{G}>\mathrm{C}$ (cases: G/G 72.2\% (52 patients), G/C 22.2\% $(n=16)$, C/C 5.6\% $(n=4)$; controls: G/G 52.8\% $(n=38), \mathrm{G} / \mathrm{C} 37.5 \%(n=27)$, C/C 9.7\% $(n=7)$; cases/controls $\mathrm{G} / \mathrm{G}, P=0.0248)$ and IVS6 $+62 \mathrm{~A}>\mathrm{G}$ polymorphisms (cases: $\mathrm{G} / \mathrm{G} \quad 88.9 \%$ $(n=64)$, G/A $4.1 \%(n=3)$, A/A 7.0\% $(n=5)$; controls: $\mathrm{G} / \mathrm{G}$ $65.1 \%(n=192), \mathrm{G} / \mathrm{A} 29.5 \%(n=87), \mathrm{A} / \mathrm{A} 5.4 \%(n=16)$; cases/controls: G/G, $P<0.0001 ; \mathrm{G} / \mathrm{A}, P<0.0001)$. For IVS2+ $38 \mathrm{G}>\mathrm{C}$ and for IVS6 $+62 \mathrm{~A}>\mathrm{G}$ we observed a good correlation to the GVS database (intron 2 SNP no. 1642785 : $\mathrm{MAF}=26 \%$; intron $6 \mathrm{SNP}$ no. 1625895: $\mathrm{MAF}=18 \%$ ).
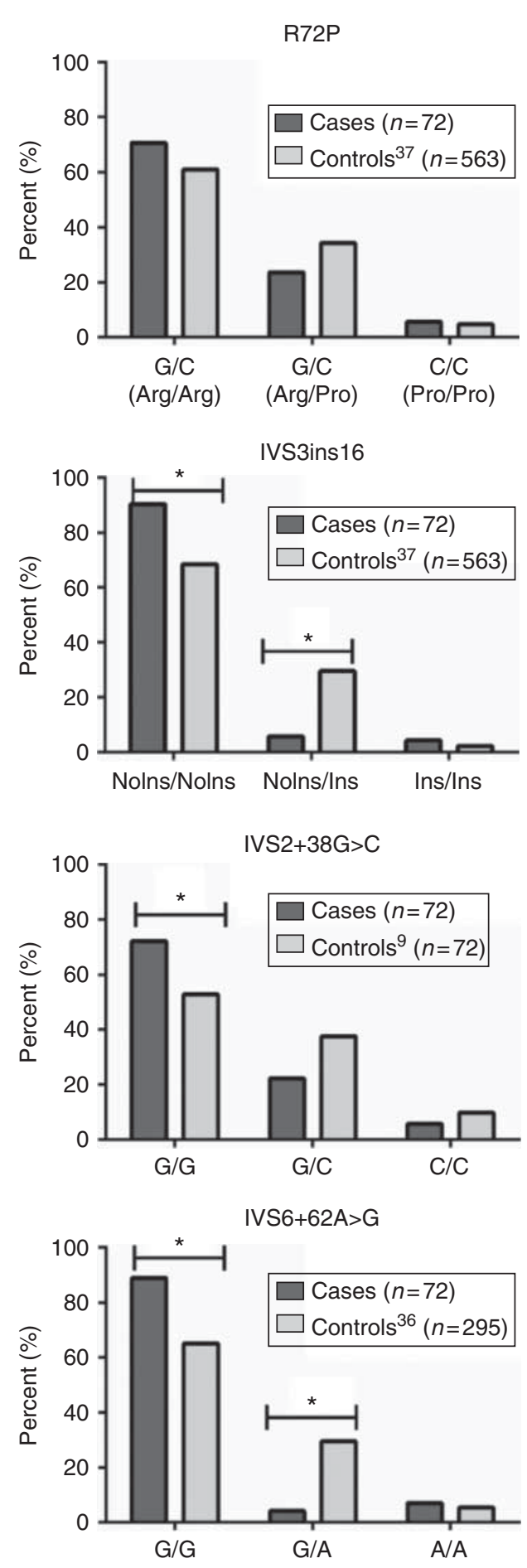

Figure 3

Distribution of R72P, IVS2 + 38G > C, IVS3ins 16 and IVS6 + 62A $>$ G polymorphisms in 72 adult $A C C$ patients compared with healthy control groups available in references $(9,36,37)$. ${ }^{*} P$ value $<0.05$. Data are shown as \% but statistical analysis was performed with absolute values as described in the text (see the Results section). 
The distribution of the genotype frequencies in $\mathrm{R} 72 \mathrm{P}$ $(P=0.982), \quad$ IVS $2+38 \mathrm{G}>\mathrm{C} \quad(P=0.501), \quad$ IVS3ins16 $(P=0.226)$, and IVS6 $+62 \mathrm{~A}>\mathrm{G}(P=0.148)$ polymorphisms among the control groups is in agreement with those expected under the Hardy-Weinberg equilibrium. The distribution of the genotype frequencies in $\mathrm{R} 72 \mathrm{P}$ $(P=0.1329)$ and IVS $2+38 \mathrm{G}>\mathrm{C}(P=0.089)$ among our ACC patients is also in agreement with Hardy-Weinberg equilibrium. We found a deviation from Hardy-Weinberg equilibrium in ACC patients for the IVS3ins16 and IVS $6+62 \mathrm{~A}>\mathrm{G}$ polymorphisms most likely due to the small sample size. For all investigated intronic TP53 polymorphisms, a higher incidence of the more frequent allele and a lower incidence of the less frequent allele were found in ACC patients compared with the control groups (Fig. 3).

\section{TP53 polymorphisms and impact on prognosis}

Survival analysis was conducted for all described polymorphisms. Patients with the less frequent genotype of R72P polymorphism (G/C (Arg/Pro) and C/C (Pro/Pro)) showed a significantly shorter OS than patients with the common genotype (G/G (Arg/Arg): median, 19.4 vs 73.5 months; HR, 0.47; 95\% CI, 0.20-0.82; $P=0.012$; Fig. 4 and Table 2). Similarly, patients with the less frequent genotype of IVS2 $+38 \mathrm{G}>\mathrm{C}$ polymorphism $(\mathrm{G} / \mathrm{C}, \mathrm{C} / \mathrm{C})$ showed a significantly shorter $O S$ in contrast to the common genotype (G/G) (median, 18.7 vs 73.5 months; HR, 0.50; 95\% CI, 0.22-0.88; $P=0.021$; Fig. 4 and Table 2 ).

In our cohort, 49 patients $(68.1 \%)$ were homozygous carriers of the common allele of each of the investigated polymorphisms. The remaining 23 patients (31.9\%) were carriers of one or more polymorphisms with the less common allele, with a high percentage in these patients $(82.6 \%)$ having two or more of the less common TP53 polymorphisms (Fig. 5). Twenty-one of these patients (91.3\%) were carriers of the less common allele of the R72P polymorphism and 20 patients $(87.0 \%)$ were carriers of the less common allele of the IVS $2+38 \mathrm{G}>\mathrm{C}$ polymorphism. Taking a closer look, our study showed that about $78.3 \%$ of patients with the less common allele of the R72P polymorphism were also carriers of the less common allele of the IVS2 + 38G $>$ C polymorphism (Fig. 5), precluding a reliable analysis of the individual contribution of the respective polymorphism. Moreover, $34.8 \%$ of the patients who were carriers of these two polymorphisms additionally showed one or two of the rare variants of the other two analyzed polymorphisms (Fig. 5), further hindering the analysis of the impact of individual polymorphisms. Therefore, we combined all patients with at least one less common allele of the respective polymorphism for analysis of the clinical data. This univariable analysis showed a significant impact of the
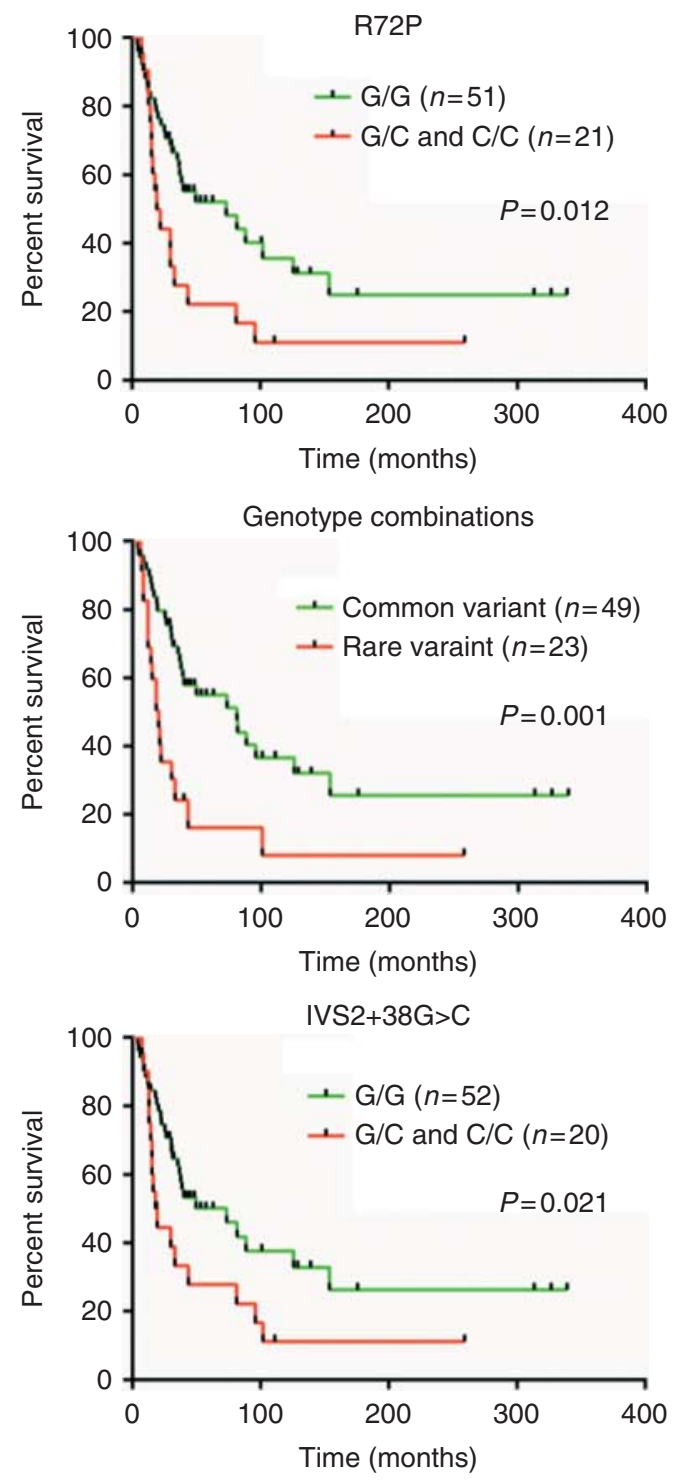

\section{Figure 4}

Impact of the less common alleles of R72P, IVS2 +38G $>C$, and the combination of the common allele of each of the investigated polymorphism vs the less common allele on overall survival of 72 ACC patients. Common variant: patients were carriers of the common allele of each of the four investigated polymorphisms (R72P: G/G (Arg/Arg), IVS2 + 38G > C (G/G), IVS3ins16 (Nolns/Nolns), IVS6 +62A > G (G/G); rare variant: patients were carriers of one or more polymorphisms with the less common allele R72P: (G/C, C/C), IVS2 + 38G >C (G/C, C/C), IVS3ins16 (Nolns/Ins, Ins/Ins), IVS6+62A > G (G/A, A/A). 
Table 2 Univariable regression analyses of TP53 polymorphisms in patients.

\begin{tabular}{l} 
TP53 \\
polymorphisms \\
\hline R72P \\
G/G (Arg/Arg) \\
G/C (Arg/Pro) \\
C/C (Pro/Pro) \\
IVS2+38G $>C$ \\
G/G \\
G/C \\
C/C \\
IVS3ins16 \\
Nolns/Nolns \\
Nolns/Ins \\
Ins/Ins \\
IVS6+62A $>$ G \\
G/G \\
G/A \\
A/A
\end{tabular}

$\begin{array}{r} \\ \boldsymbol{n} \\ \hline \\ 51 \\ 17 \\ 4 \\ 52 \\ 16 \\ 4 \\ 65 \\ 4 \\ 3 \\ 64 \\ 3 \\ 5 \\ \hline\end{array}$

\begin{tabular}{c}
$\begin{array}{c}\text { Median survival } \\
\text { (months) }\end{array}$ \\
\hline \\
73.5 \\
19.4 \\
28.3 \\
73.5 \\
18.7 \\
28.3 \\
40.0 \\
33.1 \\
43.6 \\
40 \\
59.9 \\
33.1
\end{tabular}

\begin{tabular}{|c|c|}
\hline$P^{*}$ & $\begin{array}{l}\text { Frequent allele/ } \\
\text { less frequent allele }\end{array}$ \\
\hline \multicolumn{2}{|l|}{0.021} \\
\hline & $\begin{array}{l}\text { G/G (Arg/Arg) } \\
\text { G/C (Arg/Pro) } \\
\text { C/C (Pro/Pro) }\end{array}$ \\
\hline \multicolumn{2}{|c|}{0.037} \\
\hline & $\mathrm{G} / \mathrm{G}$ \\
\hline & $\mathrm{G} / \mathrm{C}$ \\
\hline & $\mathrm{C} / \mathrm{C}$ \\
\hline \multicolumn{2}{|l|}{0.877} \\
\hline & Nolns/Nolns \\
\hline & Nolns/Ins \\
\hline & Ins/Ins \\
\hline \multicolumn{2}{|c|}{0.859} \\
\hline & $\mathrm{G} / \mathrm{G}$ \\
\hline & $\mathrm{G} / \mathrm{A}$ \\
\hline & A/A \\
\hline
\end{tabular}

\begin{tabular}{l}
\hline $\boldsymbol{n}$ \\
\hline 51 \\
21 \\
52 \\
20 \\
65 \\
7 \\
64 \\
8 \\
\hline
\end{tabular}
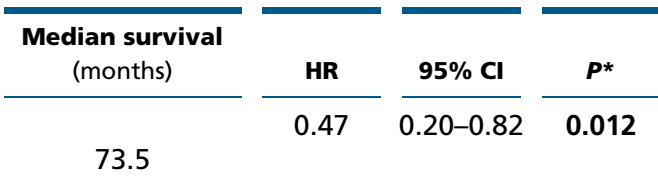

19.4

73.5

$0.50 \quad 0.22-0.88$

0.021

18.7

40.0

$0.92 \quad 0.38-2.24 \quad 0.863$

38.3

40

$0.79 \quad 0.33-1.89$

0.597

8

33.1 examined parameters on survival concerning TP53 polymorphisms (HR, 2.56; 95\% CI, 1.66-7.07; $P=0.0010$ ). In addition, age at primary diagnosis, ENSAT stage, Ki67, involvement of lymph nodes, and vessel infiltration also affected the outcome. Of note, the median survival was 20 months for ACC patients with one or more polymorphisms with the less common allele compared with a median survival of 81 months in patients with the common allele in all examined polymorphisms (Table 3 and Fig. 4). The follow-up time of patients alive with one or more polymorphisms of the rare variant was 30 months (9-258) and the follow-up time of patients with the common variant was 53.5 months (28.8-339).

To evaluate whether the worse survival of the less common variant was influenced by confounding factors (e.g. higher Ki67, older age, and all rare variants are ENSAT stage IV) we analyzed the relationship between the common and the rare variants of TP53 polymorphisms and the baseline clinical features of adult ACC patients (Table 4). There were no significant correlations between the less common variants and all tested prognostic parameters (age at PD, ENSAT stage, sex, tumor size, Ki67, involvement of lymph nodes, capsule infiltration, and vessel infiltration).

As the full set of selected prognostic parameters was not available for all the 72 patients, the multivariable regression analysis was carried out for only 41 patients. Despite the low number of affected cases, the presence of at least one of the less common TP53 polymorphisms remained a significant predictor of survival (HR, 2.84; 95\% CI, 1.52-7.17; $P=0.037$ ) after multivariable adjustment (Table 3).

\section{Discussion}

Our study in patients with ACC led to two major findings: significant differences in the prevalence of three out of four TP53 polymorphisms and a prognostic role of TP53 alleles on OS. Intriguingly, the prevalence of the common alleles was increased in ACC patients compared with

\begin{tabular}{|c|c|c|c|c|c|c|c|}
\hline Patient & Sex & $\begin{array}{l}\text { Age at } \\
\text { PD }\end{array}$ & $\begin{array}{c}\text { Survival } \\
\text { (in months) }\end{array}$ & $\mathrm{R} 72 \mathrm{P}$ & $\begin{array}{c}\text { IVS2+38 } \\
\text { G>C }\end{array}$ & $\begin{array}{l}\text { IVS3 } \\
\text { ins16 }\end{array}$ & $\begin{array}{c}\text { IVS6+62 } \\
\quad A>G\end{array}$ \\
\hline 1 & $\mathrm{~m}$ & 36 & 30 & $\square$ & $\square$ & $\square$ & $\square$ \\
\hline 2 & $f$ & 44 & 12 & $\square$ & $\square$ & $\square$ & $\square$ \\
\hline 3 & $f$ & 40 & 21 & & & & \\
\hline 4 & $\mathrm{~m}$ & 18 & 9 & $\square$ & & & 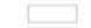 \\
\hline 5 & $f$ & 51 & 16 & $\square$ & $\square$ & & 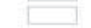 \\
\hline 6 & $f$ & 24 & 29 & $\square$ & $\square$ & & $\square$ \\
\hline 7 & $\mathrm{~m}$ & 44 & 19 & & $\square$ & & 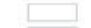 \\
\hline 8 & $f$ & 49 & 13 & & 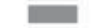 & & $\square$ \\
\hline 9 & $f$ & 38 & 111 & $\square$ & $\square$ & $\square$ & 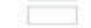 \\
\hline 10 & $f$ & 31 & 95 & $\square$ & $\square$ & $\square$ & 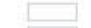 \\
\hline 11 & $\mathrm{~m}$ & 60 & 81 & & & & \\
\hline 12 & $\mathrm{~m}$ & 69 & 7 & $\square$ & $\square$ & $\square$ & $\square$ \\
\hline 13 & $\mathrm{~m}$ & 58 & 15 & $\square$ & $\square$ & & $\square$ \\
\hline 14 & $f$ & 65 & 18 & & & & \\
\hline 15 & $f$ & 77 & 14 & $\square$ & $\square$ & $\square$ & $\square$ \\
\hline 16 & $f$ & 60 & 14 & $\square$ & $\square$ & $\square$ & $\square$ \\
\hline 17 & $\mathrm{~m}$ & 42 & 101 & 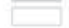 & $\square$ & $\square$ & \\
\hline 18 & $f$ & 35 & 43 & 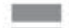 & 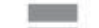 & $\square$ & 단 \\
\hline 19 & $f$ & 32 & 8 & 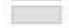 & $\square$ & $\square$ & $\square$ \\
\hline 20 & $\mathrm{~m}$ & 55 & 12 & $\square$ & $\square$ & $\square$ & $\square$ \\
\hline 21 & $\mathrm{~m}$ & 61 & 33 & & & & $\square$ \\
\hline 22 & $\mathrm{~m}$ & 49 & 18 & $\square$ & $\square$ & $\square$ & $\square$ \\
\hline 23 & $\mathrm{~m}$ & 40 & 258 & $\square$ & $\square$ & $=$ & $\square$ \\
\hline
\end{tabular}

\section{Figure 5}

Distribution of the less frequent genotype polymorphism variants in 23 adult ACC patients. Age at PD in years; $m$, male; $\mathrm{f}$, female; white rectangle, common variant homozygous; light grey rectangle, heterozygous; dark grey rectangle, rare variant homozygous. 
Table 3 Univariable and multivariable Cox regression analyses for risk of death in the adult ACC patients. Common variant: patients were carriers of the common allele of each of the investigated polymorphisms (R72P: G/G (Arg/Arg), IVS2 + 38G > C (G/G), IVS3ins16 (Nolns/Nolns), IVS6 +62A $>$ G (G/G); rare variant: patients were carriers of one or more polymorphisms with the less common allele R72P: (G/C, C/C), IVS2 + 38G > C (G/C, C/C), IVS3ins16 (Nolns/Ins, Ins/Ins), IVS6+62A > G (G/A, A/A). As the full set of selected prognostic parameters was not available for all 72 patients, the multivariable regression analysis was performed for only 41 patients.

\begin{tabular}{l}
\hline \\
\\
\hline TP53 polymorphisms \\
Common variant \\
Rare variant \\
Age at PD \\
$\leq 46$ years \\
$>46$ years \\
ENSAT stage \\
I-III \\
IV \\
Sex \\
Male \\
Female \\
Tumor size \\
$\leq 10.5 \mathrm{~cm}$ \\
$>10.5 \mathrm{~cm}$ \\
Ki67 \\
$<10$ \\
$\geq 10$ \\
Involvement of lymph nodes \\
None \\
Yes \\
Capsule infiltration \\
None \\
Yes \\
Vessel infiltration \\
None \\
Yes \\
\hline
\end{tabular}

$\begin{array}{r}\hline \text { n } \\ \hline \\ \hline 49 \\ 23 \\ 35 \\ 37 \\ 49 \\ 23 \\ 31 \\ 41 \\ 36 \\ 34 \\ 18 \\ 38 \\ 46 \\ 8 \\ 32 \\ 26 \\ 21 \\ 40 \\ \hline\end{array}$

Univariable analysis

Median survival

(months)

\section{0}

20.0

81.8

35.4

81.8

18.0

48.2

49.2

36.6

43.6

88.5

31.3

81.0

22.8

73.5

37.5

95.9

33.1
Multivariable analysis

Multivariable analysis

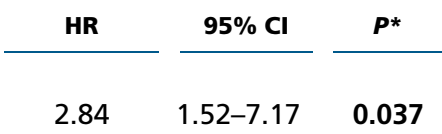

$1.93 \quad 1.05-3.52 \quad 0.0325$

17

$5.26 \quad 2.48-11.10<0.0001 \quad 33$

5.71

$1.78-17.40$

0.002

$1.03 \quad 0.56-1.85 \quad 0.9364$

$1.33 \quad 0.73-2.40$

0.3417

$3.69 \quad 1.29-5.34$

0.0079

22

0.89

$0.37-2.12$

0.788

$8.16 \quad 2.34-28.4$

$\mathbf{0 . 0 0 1 0} 35$

1.54

$0.38-6.22$

0.542

$1.29 \quad 0.66-2.54 \quad 0.4460$

$2.43 \quad 1.25-4.72$

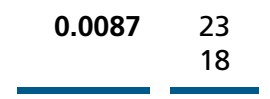

0.59

$0.22-1.61$

0.307

PD, primary diagnosis; HR, hazard ratio. ${ }^{\star} P<0.05$ was considered significant.

controls, whereas poor prognosis was associated with the less common alleles.

The prevalence of the alleles of the different TP53 polymorphisms varies widely both in reference populations and in cancer cohorts. Furthermore, highly variable results have been reported concerning the association of specific polymorphisms with cancer risk $(2,7,15,16,17,18)$. For example, while Murata et al. (18) reported lung cancer to be associated with the arginine variant of the R72P polymorphism, others observed a higher prevalence of the proline variant compared with controls in such patients (17). Similarly, in the only previous study on TP53 polymorphims in ACC patients, a threefold higher prevalence of the proline variant of the R72P polymorphism compared with controls was observed (19), although in our study no such difference of TP53 R72P alleles was observed using both a larger patient sample and a larger control group. However, although our patient sample is large for a rare cancer like ACC, it is still small in comparison with studies in other malignancies $(7,16,37,38)$. As the less common alleles have been shown to negatively affect p53 function (2, 10, 13, 14, 39), a higher prevalence of the more common alleles in ACC appears at first glance counterintuitive. However, such association may be indirect by affecting certain risk factors for ACC. For example, meta-analysis of TP53 polymorphisms in hepatocellular carcinoma indicated that the R72P polymorphism may be associated with liver cancer and that difference in genotype distribution may be associated with race, sex, and also with chronic hepatitis virus as a possible risk factor (39). Due to the rarity of ACC, no risk factors have been established up to now for this malignancy. However, the recent development of a European patient registry holds the potential to change this picture. 
Table 4 Relationship between common and rare variants of TP53 polymorphisms and baseline clinical features of adult ACC patients. Data is presented as $n(\%)$. Common variant: patients were carriers of the common allele of each of the investigated polymorphisms (R72P: G/G (Arg/Arg), IVS2+38G >C (G/G), IVS3ins16 (Nolns/Nolns), IVS6+62A $>$ G (G/G); rare variant: patients were carriers of one or more polymorphisms with the less common allele R72P: (G/C, C/C), IVS2+38G >C (G/C,C/C), IVS3ins16 (Nolns/Ins, Ins/Ins), IVS6+62A > G (G/A, A/A). Unfortunately, not all data were available in all patients. For this reason, the number of patients varied.

\begin{tabular}{|c|c|c|c|}
\hline & $\begin{array}{l}\text { Common } \\
\text { variants }\end{array}$ & $\begin{array}{c}\text { Rare } \\
\text { variants }\end{array}$ & $P^{*}$ \\
\hline TP53 polymorphisms & $49(68.1)$ & $23(31.9)$ & \\
\hline \multicolumn{4}{|l|}{ Sex } \\
\hline Male & $19(38.8)$ & $11(47.8)$ & \multirow[t]{2}{*}{0.64} \\
\hline Female & $30(61.2)$ & $12(52.2)$ & \\
\hline \multicolumn{4}{|l|}{ Age at PD (years) } \\
\hline$<46$ & $26(53.0)$ & $12(52.2)$ & \multirow[t]{2}{*}{0.94} \\
\hline$>46$ & $23(47.0)$ & $11(47.8)$ & \\
\hline \multicolumn{4}{|l|}{ ENSAT stage } \\
\hline I & $3(6.1)$ & $2(8.7)$ & \multirow[t]{4}{*}{0.08} \\
\hline II & $21(42.8)$ & $4(17.4)$ & \\
\hline III & 9 (18.4) & 10 (43.5) & \\
\hline IV & $16(32.7)$ & 7 (30.4) & \\
\hline \multicolumn{4}{|l|}{ Tumor size $(\mathrm{cm})$} \\
\hline$\leq 10.5$ & $25(52.1)$ & $11(50)$ & \multirow[t]{2}{*}{0.87} \\
\hline$>10.5$ & $23(47.9)$ & $11(50)$ & \\
\hline \multicolumn{4}{|l|}{$\mathrm{Ki} 67-n(\%)$} \\
\hline$<10$ & $14(35.9)$ & $4(23.5)$ & \multirow[t]{2}{*}{0.55} \\
\hline$\geq 10$ & $25(64.1)$ & $13(76.5)$ & \\
\hline \multicolumn{4}{|c|}{ Involvement of lymph nodes } \\
\hline None & $30(83.3)$ & $16(88.8)$ & \multirow[t]{2}{*}{0.89} \\
\hline Yes & $6(16.7)$ & $2(11.2)$ & \\
\hline \multicolumn{4}{|l|}{ Capsule infiltration } \\
\hline None & $24(60.0)$ & $8(44.4)$ & \multirow[t]{2}{*}{0.41} \\
\hline Yes & $16(40.0)$ & $10(55.6)$ & \\
\hline \multicolumn{4}{|l|}{ Vessel infiltration } \\
\hline None & $17(40.5)$ & $4(21.1)$ & \multirow[t]{2}{*}{0.23} \\
\hline Yes & $25(59.5)$ & $15(78.9)$ & \\
\hline
\end{tabular}

PD, primary diagnosis; NS, not significant. $P$ value by $\chi^{2}$ test $\left({ }^{*} P<0.05\right.$ was considered significant).

The probably clinically more relevant observation derived from this study is the prognostic impact of some less common TP53 alleles on survival. As the majority of patients exhibited more than one of the less common alleles, it was not possible to dissect the role of individual polymorphisms. In particular, the less common genotypes of R72P and IVS2 + 38C $>$ G often occurred together. Both polymorphisms have been described to belong to the same haplotype block, which may explain the similar pattern with regard to patient outcome. Importantly, the association between these genotypes and OS remained significant in multivariable analysis, together with tumor stage.
Recently it has been confirmed that p53 alterations are associated with an aggressive phenotype in ACC and poor prognosis (40). Thus one might speculate that even minor impairment of p53 function caused by certain TP53 polymorphisms might amplify additional somatic alterations (e.g. loss of the other allele).

TP53 mutations caused by various carcinogens are often discussed in the literature to be associated with a less aggressive behavior (41). Two recent studies have now shown that also in adults with ACC, TP53 germline mutations occur in a relevant percentage of patients $(31,42)$. Accordingly, analysis of the TP53 gene has been suggested in adult patients with ACC, as it may impact on patient care and surveillance of affected relatives (43). Such screening for TP53 mutations would hold the potential to also characterize TP53 polymorphisms thereby generating possibly important prognostic information.

In summary, analysis of TP53 polymorphisms may confer relevant prognostic information in ACC. Additional ACC cohorts are required to confirm that certain TP53 polymorphisms should be considered as a risk factor for ACC.

Declaration of interest

The authors declare that there is no conflict of interest that could be perceived as prejudicing the impartiality of the research reported.

\section{Funding}

This work was supported by grants of the Deutsche Krebshilfe (grant number 107111 to M Fassnacht), the IZKF Wuerzburg (grant number F-124 to $S$ Hahner), and the Else-Kroener-Fresenius-Stiftung (grant number 2010_EKES.29).

\section{Acknowledgements}

The authors are grateful to all colleagues and patients who provided clinical data and tissue material for the German Adrenocortical Carcinoma (ACC) Registry. They also appreciate the support of Prof. W Saeger (Marienkrankenhaus Hamburg) and of the members of the German ACC Registry Group (especially Michaela Haaf).

\section{References}

1 Petitjean A, Mathe E, Kato S, Ishioka C, Tavtigian SV, Hainaut P \& Olivier M. Impact of mutant p53 functional properties on TP53 mutation patterns and tumor phenotype: lessons from recent developments in the IARC TP53 database. Human Mutation 200728 622-629. (doi:10.1002/humu.20495)

2 Whibley C, Pharoah P \& Hollstein M. p53 polymorphisms: cancer implications. Nature Reviews. Cancer 2009 95-107. (doi:10.1038/ nrc2584) 
3 Levine AJ, Hu W \& Feng Z. The P53 pathway: what questions remain to be explored? Cell Death and Differentiation 200613 1027-1036. (doi:10.1038/sj.cdd.4401910)

4 Runnebaum IB, Tong XW, König R, Zhao H, Körner K, Atkinson EN, Kreienberg R, Kieback DG \& Hong Z [corrected to Zhao H]. p53-based blood test for p53PIN3 and risk for sporadic ovarian cancer. Lancet 1995 345 994. (doi:10.1016/S0140-6736(95)90745-9)

5 Wu X, Zhao H, Amos CI, Shete S, Makan N, Hong WK, Kadlubar FF \& Spitz MR. p53 genotypes and haplotypes associated with lung cancer susceptibility and ethnicity. Journal of the National Cancer Institute 2002 94 681-690. (doi:10.1093/jnci/94.9.681)

6 Gemignani F, Moreno V, Landi S, Moullan N, Chabrier A, GutierrezEnriquez S, Hall J, Guino E, Peinado MA, Capella G et al. A TP53 polymorphism is associated with increased risk of colorectal cancer and with reduced levels of TP53 mRNA. Oncogene 200423 1954-1956. England. (doi:10.1038/sj.onc.1207305)

7 Costa S, Pinto D, Pereira D, Rodrigues H, Cameselle-Teijeiro J, Medeiros R \& Schmitt F. Importance of TP53 codon 72 and intron 3 duplication 16bp polymorphisms in prediction of susceptibility on breast cancer. BMC Cancer 20088 32. (doi:10.1186/1471-2407-8-32)

8 Pleasants L \& Hansen M. Identification of a polymorphism in intron 2 of the p53 gene. Human Genetics 199493 607-608. (doi:10.1007/ BF00202835)

9 Høgdall EV, Kjaer SK, Glud E, Christensen L, Blaakaer J, Vuust J, Bock JE, Norgaard-Pedersen B \& Hogdall CK. Evaluation of a polymorphism in intron 2 of the p53 gene in ovarian cancer patients. From the Danish "Malova" Ovarian Cancer Study. Anticancer Research 200323 3397-3404.

10 Pietsch EC, Humbey O \& Murphy ME. Polymorphisms in the p53 pathway. Oncogene 200625 1602-1611. (doi:10.1038/sj.onc.1209367)

11 Beckman G, Birgander R, Sjalander A, Saha N, Holmberg PA, Kivela A \& Beckman L. Is p53 polymorphism maintained by natural selection? Human Heredity 199444 266-270. (doi:10.1159/000154228)

12 Sjalander A, Birgander R, Saha N, Beckman L \& Beckman G. p53 polymorphisms and haplotypes show distinct differences between major ethnic groups. Human Heredity 199646 41-48. (doi:10.1159/ $000154324)$

13 Dumont P, Leu JI, Della Pietra AC III, George DL \& Murphy M. The codon 72 polymorphic variants of p53 have markedly different apoptotic potential. Nature Genetics 200333 357-365. United States. (doi:10.1038/ng1093)

14 Bergamaschi D, Samuels Y, Sullivan A, Zvelebil M, Breyssens H, Bisso A, Del Sal G, Syed N, Smith P, Gasco M et al. iASPP preferentially binds p53 proline-rich region and modulates apoptotic function of codon 72-polymorphic p53. Nature Genetics 200638 1133-1141. (doi:10.1038/ ng1879)

15 Hrstka R, Beranek M, Klocova K, Nenutil R \& Vojtesek B. Intronic polymorphisms in TP53 indicate lymph node metastasis in breast cancer. Oncology Reports 200922 1205-1211.

16 Wang-Gohrke S, Rebbeck TR, Besenfelder W, Kreienberg R \& Runnebaum IB. p53 germline polymorphisms are associated with an increased risk for breast cancer in German women. Anticancer Research 199818 2095-2099.

17 Kawajiri K, Nakachi K, Imai K, Watanabe J \& Hayashi S. Germ line polymorphisms of p53 and CYP1A1 genes involved in human lung cancer. Carcinogenesis 199314 1085-1089. (doi:10.1093/carcin/ 14.6.1085)

18 Murata M, Tagawa M, Kimura M, Kimura H, Watanabe S \& Saisho H. Analysis of a germ line polymorphism of the p53 gene in lung cancer patients; discrete results with smoking history. Carcinogenesis $1996 \mathbf{1 7}$ 261-264. (doi:10.1093/carcin/17.2.261)

19 Ignaszak-Szczepaniak M, Horst-Sikorska W, Sawicka J, Kaczmarek M \& Slomski R. The TP53 codon 72 polymorphism and predisposition to adrenocortical cancer in Polish patients. Oncology Reports 200616 $65-71$.
20 Osorio A, Martinez-Delgado B, Pollan M, Cuadros M, Urioste M, Torrenteras C, Melchor L, Diez O, De La Hoya M, Velasco E et al. A haplotype containing the p53 polymorphisms Ins16bp and Arg72Pro modifies cancer risk in BRCA2 mutation carriers. Human Mutation 2006 27 242-248. (doi:10.1002/humu.20283)

21 Boldrini L, Gisfredi S, Ursino S, Lucchi M, Greco G, Mussi A, Donati V \& Fontanini G. Effect of the p53 codon 72 and intron 3 polymorphisms on non-small cell lung cancer (NSCLC) prognosis. Cancer Investigation 200826 168-172. United States. (doi:10.1080/07357900701788023)

22 Kerkhofs TM, Verhoeven RH, Van der Zwan JM, Dieleman J, Kerstens MN, Links TP, Van de Poll-Franse LV \& Haak HR. Adrenocortical carcinoma: a population-based study on incidence and survival in the Netherlands since 1993. European Journal of Cancer 201349 2579-2586. (doi:10.1016/j.ejca.2013.02.034)

23 Kebebew E, Reiff E, Duh QY, Clark OH \& McMillan A. Extent of disease at presentation and outcome for adrenocortical carcinoma: have we made progress? World Journal of Surgery 200630 872-878. (doi:10.1007/ s00268-005-0329-x)

24 Fassnacht M, Johanssen S, Quinkler M, Bucsky P, Willenberg HS, Beuschlein F, Terzolo M, Mueller HH, Hahner S, Allolio B et al. Limited prognostic value of the 2004 International Union Against Cancer staging classification for adrenocortical carcinoma: proposal for a Revised TNM Classification. Cancer 2009115 243-250. (doi:10.1002/ cncr.24030)

25 Assié G, Antoni G, Tissier F, Caillou B, Abiven G, Gicquel C, Leboulleux S, Travagli JP, Dromain C, Bertagna X et al. Prognostic parameters of metastatic adrenocortical carcinoma. Journal of Clinical Endocrinology and Metabolism 200792 148-154. (doi:10.1210/jc.20060706)

26 Miller BS, Gauger PG, Hammer GD, Giordano TJ \& Doherty GM. Proposal for modification of the ENSAT staging system for adrenocortical carcinoma using tumor grade. Langenbeck's Archives of Surgery 2010 395 955-961. (doi:10.1007/s00423-010-0698-y)

27 Bourdeau I, MacKenzie-Feder J \& Lacroix A. Recent advances in adrenocortical carcinoma in adults. Current Opinion in Endocrinology, Diabetes, and Obesity 201320 192-197. (doi:10.1097/MED. 0b013e3283602274)

28 Abiven G, Coste J, Groussin L, Anract P, Tissier F, Legmann P, Dousset B, Bertagna X \& Bertherat J. Clinical and biological features in the prognosis of adrenocortical cancer: poor outcome of cortisolsecreting tumors in a series of 202 consecutive patients. Journal of Clinical Endocrinology and Metabolism 200691 2650-2655. (doi:10.1210/ jc.2005-2730)

29 Berruti A, Terzolo M, Sperone P, Pia A, Casa SD, Gross DJ, Carnaghi C, Casali P, Porpiglia F, Mantero F et al. Etoposide, doxorubicin and cisplatin plus mitotane in the treatment of advanced adrenocortical carcinoma: a large prospective phase II trial. Endocrine-Related Cancer 200512 657-666. England. (doi:10.1677/erc.1.01025)

30 Varley JM, Chapman P, McGown G, Thorncroft M, White GR, Greaves MJ, Scott D, Spreadborough A, Tricker KJ, Birch JM et al. Genetic and functional studies of a germline TP53 splicing mutation in a Li-Fraumeni-like family. Oncogene 199816 3291-3298. (doi:10.1038/ sj.onc.1201878)

31 Herrmann LJ, Heinze B, Fassnacht M, Willenberg HS, Quinkler M, Reisch N, Zink M, Allolio B \& Hahner S. TP53 germline mutations in adult patients with adrenocortical carcinoma. Journal of Clinical Endocrinology and Metabolism 201297 E476-E485. (doi:10.1210/ jc.2011-1982)

32 Koschker AC, Fassnacht M, Hahner S, Weismann D \& Allolio B. Adrenocortical carcinoma - improving patient care by establishing new structures. Experimental and Clinical Endocrinology \& Diabetes 2006114 45-51. (doi:10.1055/s-2006-923808)

33 Brix D, Allolio B, Fenske W, Agha A, Dralle H, Jurowich C, Langer P, Mussack T, Nies C, Riedmiller H et al. Laparoscopic versus open adrenalectomy for adrenocortical carcinoma: surgical and oncologic 
outcome in 152 patients. European Urology 201058 609-615. (doi:10.1016/j.eururo.2010.06.024)

34 Fassnacht M, Johanssen S, Fenske W, Weismann D, Agha A, Beuschlein F, Führer D, Jurowich C, Quinkler M, Petersenn S et al. Improved survival in patients with stage II adrenocortical carcinoma followed up prospectively by specialized centers. Journal of Clinical Endocrinology and Metabolism 201095 4925-4932. (doi:10.1210/ jc.2010-0803)

35 Weiss LM. Comparative histologic study of 43 metastasizing and nonmetastasizing adrenocortical tumors. American Journal of Surgical Pathology 19848 163-169. (doi:10.1097/00000478-198403000-00001)

36 De Feo E, Persiani R, La Greca A, Amore R, Arzani D, Rausei S, D’Ugo D, Magistrelli P, van Duijn C, Ricciardi G et al. A case-control study on the effect of p53 and p73 gene polymorphisms on gastric cancer risk and progression. Mutation Research 2009675 60-65. (doi:10.1016/ j.mrgentox.2009.02.009)

37 Tan X, Nieters A, Hoffmeister M, Beckmann L, Brenner H \& ChangClaude J. Genetic polymorphisms in TP53, nonsteroidal anti-inflammatory drugs and the risk of colorectal cancer: evidence for geneenvironment interaction? Pharmacogenetics and Genomics 200717 639-645. (doi:10.1097/FPC.0b013e3280d5121c)

38 Rogler A, Rogenhofer M, Borchardt A, Lunz JC, Knoell A, Hofstaedter F, Tannapfel A, Wieland W, Hartmann A \& Stoehr R. P53 codon 72 (Arg72Pro) polymorphism and prostate cancer risk: association between disease onset and proline genotype. Pathobiology 201178 193-200. (doi:10.1159/000326767)

39 Chen X, Liu F, Li B, Wei YG, Yan LN \& Wen TF. p53 codon 72 polymorphism and liver cancer susceptibility: a meta-analysis of epidemiologic studies. World Journal of Gastroenterology $2011 \mathbf{1 7}$ 1211-1218. (doi:10.3748/wjg.v17.i9.1211)

40 Ragazzon B, Libe R, Gaujoux S, Assie G, Fratticci A, Launay P, Clauser E, Bertagna $\mathrm{X}$, Tissier F, de Reynies A \& Bertherat J. Transcriptome analysis reveals that $\mathrm{p} 53$ and $\beta$-catenin alterations occur in a group of aggressive adrenocortical cancers. Cancer Research 201021 8276-8281. (doi:10.1158/0008-5472.CAN-10-2014)

41 Rivlin N, Brosh R, Oren M \& Rotter V. Mutations in the p53 tumor suppressor gene: important milestones at the various steps of tumorigenesis. Genes \& Cancer 20112 466-474. (doi:10.1177/ 1947601911408889)

42 Raymond VM, Else T, Everett JN, Long JM, Gruber SB \& Hammer GD. Prevalence of germline TP53 mutations in a prospective series of unselected patients with adrenocortical carcinoma. Journal of Clinical Endocrinology and Metabolism 201398 E119-E125. (doi:10.1210/ jc.2012-2198)

43 Villani A, Tabori U, Schiffman J, Shlien A, Beyene J, Druker H, Novokmet A, Finlay J \& Malkin D. Biochemical and imaging surveillance in germline TP53 mutation carriers with Li-Fraumeni syndrome: a prospective observational study. Lancet Oncology 201112 559-567. (doi:10.1016/S1470-2045(11)70119-X)

Received 25 September 2013

Revised version received 18 February 2014

Accepted 21 February 2014 